\title{
CLINICAL AND NEUROLOGICAL PECULIARITIES OF PATIENT DIAGNOSTICS WITH DEGENERATIVE PATHOLOGY OF THE LUMBAR SPINE
}

\author{
Tymur Ksenzov \\ Postgraduate Student, Romodanov Neurosurgery Institute of National Academy \\ of Medical Sciences of Ukraine, Ukraine; Neurosurgeon, \\ Zaporizhzhia Regional Clinical Hospital, Ukraine \\ e-mail: ksenzovtimur@gmail.com,orcid.org/0000-0001-8305-8563
}

\section{Summary}

The problem of degenerative-dystrophic diseases is relevant due to it's high prevalence of pathology. The most common causes of lumbar spine pain are hernias of intervertebral discs and spinal canal stenosis. The lumbosacral spine is prone to present of intervertebral disc hernias due to the peculiarities of biomechanics, and is therefore the main cause of spinal surgery among adult population. The aim of this paper is is to analyze the literature and study the diagnostics of degenerative diseases of the lumbar spine. The analytical, bibliosemantic, system approach and system analysis methods were used in the work. We must use neuroimaging data for determing the localization of intervertebral disc herniation and concomitant spinal canal stenosis. Modern standardized set of research includes X-Ray functional spondylography, computed tomography (CT) and MRI. Progress in neurosurgery is more related to use MRI and CT due to it's great informativeness. Application of a complex of neuroimaging techniques for degenerative-dystrophic diseases of lumbar spine allows to reduce the number of diagnostic errors and detect diseases in the early stages.

Keywords: intervertebral disc herniation, spinal canal stenosis, computed tomography-myelography, magnetic resonance imaging, and myelography.

DOI: https://doi.org/10.23856/4431

\section{Introduction}

A recent meta-analysis showed a total of 266 million people $(3.63 \%)$ worldwide with degenerative spine disease annually (Ravindra, 2018). The problem of vertebrogenic pathology was considered quite widely. At the same time, a number of specific methodological issues remain poorly developed. It should be noted that with the apparent multifaceted nature and scope of research, many properties and mechanisms of surgical treatment require additional consideration. The clinical picture should play a significant role in the choice of the method of surgical treatment, since the radiological picture will not always correlate. There are a number of works that have made a significant contribution to the disclosure of the content, diagnosis, treatment of these pathologies, but there is virtually no works about their combination. Clinical manifestations of spinal canal stenosis (SCS) sometimes lead to disability, so solving the problem of timely diagnosis and, accordingly, proper treatment is important.

Literature data and competent non-commercial reports on clinical and neurological peculiarities of diagnosis and surgical treatment of patients with lumbar intervertebral disc herniation complicated by spinal canal stenosis during high-tech neurorehabilitation have turned out to be a fairly limited number. Thus, electromyography (EMG) is used to assess the degree 
of nerve damage in its various parts and differential diagnosis of the level of compression of the roots of herniated lumbar intervertebral discs from other neurological pathologies. To diagnose peripheral nerve damage, stimulation E.M.G is used, based on the analysis of evoked electrical muscle responses obtained by indirect electrical stimulation of the peripheral nerve. An overview spondylography of the lumbosacral spine in frontal and lateral projections is also performed using an X-ray machine (Yegorov, 2014). In addition, data from computed tomography (CT scan) of the lumbosacral spine - native, as well as contrast (CT-myelography) studies are used. According to the X-ray data of the lumbosacral spine in 2 projections (or according to CT, Magnetic Resonance Imaging - MRI), the following are determined: symptoms of damage to the bone-articular structures of the spinal segment, displacement of the bone-articular structures, the width of the spinal canal (Mysliwiec et al, 2010).

Accidental findings in the visualization are defined as previously undetected abnormalities that were unexpectedly identified and not related to the purpose of the survey. MRI of the lumbar spine can reveal both clinically insignificant accidental abnormalities of the spine and extraspinal, which can later even can explain the patient's symptoms. Identifying such findings assign various practical and ethical issues regarding clinical management. In lumbar spine magnetic resonance imaging (MRI), despite the signal saturation bands used in standard international protocols to reduce the number and severity of artifacts, accidental deviations can occur from a wide variety of diseases. Therefore, the correct assessment of changes on MRI with the conducted clinical correlation is a key component that must be considered in the process of choosing surgery for pathology of the lumbar spine (Cowley, 2016).

Given the above, the issue of adequate diagnosis of lumbar intervertebral disc herniation of patients with complicated spinal canal stenosis, and its impact on the localization and optimization of surgical treatment and the possibility of functional recovery of patients. The ambiguity of opinions gives rise to further study of the current state of the problem.

The aim of this paper is to analyze the literature and study the diagnostics of degenerative diseases of the lumbar spine.

Materials and methods. The analytical, bibliosemantic, system approach and system analysis methods were used in the work.

\section{The results of the study}

According to Andreisek et al, there is a need for consensus on clearly defined, unambiguous radiological criteria for determining lumbar spine stenosis in order to improve diagnostic accuracy and formulate reliable criteria for inclusion in clinical trials (Andreisek et al, 2013). An example is the study conducted by Steurer et al, where it is identified 14 different semiquantitative or qualitative radiologic criteria that are used for the diagnosis of LSS, though they show remarkable variability in terms of their exact individual definitions and intra- and interrater reliability (Steurer et al, 2011). Moreover, studies of the patients with LSS who were candidates for surgery did not reveal a correlation between the clinical symptoms of patients with quantitative and qualitative radiological parameters and with anatomical stenosis and the degree of stenosis, which indicates a factor-related etiology (Kuittinen et al, 2014). Researchers also noted that Instability can best be defined by standing lateral radiograms and flexion-extension radiograms, так как canal diameter measurements have not gained much consensus from radiologists, whereas qualitative measures, such as cerebrospinal fluid space obliteration, have achieved greater consensus (Zileli et al, 2020). 
Attention is drawn, in terms of the problems of our study to obtain a sufficient amount of information for the diagnosis of lumbar osteochondrosis, the results of using a non-invasive and completely safe ultrasound method (Abdullaev, 2008; Zareth et al, 2003). Thus, the diagnostic ability of ultrasonography indicated high informativeness in the visualization of the location, direction and size of protrusions, intervertebral disc herniation (Ponomarenko, 2015). Thus, during the initial diagnosis of SCC spinal canal stenosis of the lumbar spine, you can use ultrasound. ultrasound diagnostics (USD).

Another theory is based on data on the variability of the F-wave latency, which makes it possible to judge the functional state of the lumbar spine, which can be used for screening assessment in the differential diagnosis of functional and organic compression of the root. After all, the F-wave, according to modern data, is a muscle motor response that is periodically recorded during supramaximal stimulation of the mixed nerve and has a significantly greater latency than the M-response (Nazarenko et al, 2017). By its physiological nature, the F-wave is a muscle response to a return discharge resulting from antidromic stimulation of a motor neuron (Nikolaev, 2007).

Despite the importance of the work of the above mentioned researchers, they do not cover many problems, the importance of which has increased recently. Thus, in the world literature there is no single indication for the diagnosis of patients with degenerative pathology of the lumbar spine. According to MRI studies, disc herniation is often found in people without symptoms, i.e. without back and leg pain. If you still have back pain, then an MRI hernia may not be the source of the pain. Therefore, to determine the pathology of the lumbar spine, which may contribute to the development of low back pain, an acceptable method of imaging - MRI, although CT-myelography may also be a useful alternative. Opinion on this issue remains ambiguous. Not all researchers find confirmation of this. MRI is a study of the first line of spinal stenosis, intervertebral disc herniation (IDH), with the help of which it became possible to assess the localization, degree and number of stenotic lesions (Cowley, 2016), oral or caudal position of sequesters, displacement of the pulpal nucleus to the posterior longitudinal ligament, root compression, etc. [Sypytyy et al, 2004). As shown by the study of Lafian et al, no, despite the significant benefits of MRI, radiological evidence of LSS may be poorly correlated with the clinical picture (Lafian et al, 2018). Later, this idea was developed in the work of Zileli M. et al, where it is noted that the main disadvantage of this method is the lack of correlation between symptoms and the degree of stenosis (Zileli et al., 2020). Kreiner D. and others, in their study, also argue that there is insufficient evidence of a correlation between clinical symptoms and narrowing of the spinal canal on MRI, computed tomography, CT-myelography (Kreiner et al., 2013). Standard MRI sequences are unable to visualize the dynamics of changes that occur in the spine during exercise and movement (Cowley, 2016). The main disadvantage of CT is poor differentiation of the dural sac and its contents. CT myelography is used to visualize the dural sac. The main disadvantages of CT-myelography, as well as simple myelography, are the invasiveness of the study and a number of possible side reactions, such as an allergic reaction to a contrast agent, post-dural meningism, neurological disorders with mechanical damage to nerve structures. However, in a number of works, a comparative assessment of CT-myelography and magnetic resonance imaging was carried out, according to the results of which it follows that both methods are quite highly informative. CT-myelography detects more accurately changes in the bone structures, and in the work of R. Bishoff et al. there has been a greater sensitivity and specificity in determining disc herniation and spinal stenosis at the pre- and postoperative stages using CT-myelography (Bishoff et al, 1993). The pinnacle of diagnostic capabilities in assessing the state of the spinal canal at the moment is magnetic 
resonance imaging. According to Majidi et al, for the diagnosis of LSS in symptomatic and asymptomatic patients with suspected LSS, among the quantitative criteria for MRI results, the most sensitive and specific cross-section of the central spinal canal (less than $77.5 \mathrm{~mm}^{2}$ for central stenosis) and the cross-section of lateral notches (less $22.5 \mathrm{~mm}^{2}$ for lateral stenosis) (Majidi et al 2019). There is a strong correlation between neurogenic claudication and diagnostic radiological markers of LSS.

Patients with low back pain caused by a herniation often experience pain aggravation in the upright position and typically try to reduce the pain by a light flexion of the lumbar spine (McCall, 2000). This indicates that herniated discs are prone to biomechanical changes, and hence may be influenced by the positioning of the patient. Weight-bearing MRI may increase the diagnostic sensitivity of disc herniations in patients suspected of nerve root compression (Nordberg et al, 2021). Some scientists are inclined to believe that the lack of correlation may not be established by conventional MRI, but it is likely to obtain more reliable data using vertical MRI, because the human spine receives the load in the vertical position. This theory is confirmed by studies of Zhou Z. et al., who claim that the size of the dural sac on MRI is significantly reduced in the vertical position, in contrast to the horizontal position (lying on the back). Standing MRI and DCSA changes were significantly correlated with distance and lameness, with assessment of leg pain on the VAS scale in patients with LSS (Zhou et al., 2020).

As a result of our study, despite the usefulness of MRI, CT, radiological evidence of LSS, there were no reliable signs of correlation between clinical symptoms and X-ray picture of MRI in intervertebral disc herniation complicated by spinal canal stenosis, which confirms Lafian et al and accordingly entails an increase in surgical interventions (Lafian, \& Torralba, 2018).

\section{Conclusions}

To make a clinically reliable diagnosis, as a rule, instrumental diagnostic methods are required:

1. X-rays can help to determine the presence of joint degeneration, fractures, bone malformations, arthritis, tumors or infections.

2. MRI is a valuable method of visualizing morphological changes in soft tissues, including discs, spinal cord and nerve roots, but it should be supported by mandatory functional X-ray tests.

3. CT provides complete information on the morphology of the bone structures of the spine and visualization of the spinal structures in cross section.

4. Electrodiagnostic (neurophysiological) studies are needed to exclude other reasons of sensory and motor disorders, such as peripheral neuropathy and motor neuron disease.

\section{References}

Abdullayev, R.YA. (2008). Ul'trazvukovaya tomografiya pozvonochnogo dvigatel'nogo segmenta [Ultrasound tomography of the spinal motor segment]. Khar'kov : Nove slovo. [In Russian].

Andreisek, G., Imhof, M., Wertli, M., Winklhofer, S., Pfirrmann, C. W., Hodler, J., ... \& Lumbar Spinal Stenosis Outcome Study Working Group Zurich. (2013). A systematic review of semiquantitative and qualitative radiologic criteria for the diagnosis of lumbar spinal stenosis. American Journal of Roentgenology, 201(5). 
Bischoff, R. J., Rodriguez, R. P., Gupta, K., Righi, A., Dalton, J. E., \& Whitecloud, T. S. (1993). A comparison of computed tomography-myelography, magnetic resonance imaging, and myelography in the diagnosis of herniated nucleus pulposus and spinal stenosis. Journal of spinal disorders, 6(4).

Cowley, P. (2016). Neuroimaging of Spinal Canal Stenosis. Magnetic Resonance Imaging Clinics of North America, 24(3).

Kreiner, D. S., Shaffer, W. O., Baisden, J. L., Gilbert, T. J., Summers, J. T., Toton, J. F., ... Reitman, C. A. (2013). An evidence-based clinical guideline for the diagnosis and treatment of degenerative lumbar spinal stenosis (update). The Spine Journal, 13(7).

Kuittinen, P, Sipola, P, Aalto, TJ, Määttä, S, Parviainen, A, Saari, T, et al. (2014). Correlation of lateral stenosis in MRI with symptoms, walking capacity and EMG findings in patients with surgically confirmed lateral lumbar spinal canal stenosis. BMC Musculoskelet Disord.15. Lafian, A. M., \& Torralba, K. D. (2018). Lumbar spinal stenosis in older adults. Rheumatic Disease Clinics, 44(3).

Majidi, H., Shafizad, M., Niksolat, F., Mahmudi, M., Ehteshami, S., Poorali, M., \& Mardanshahi, Z. (2019). Relationship Between Magnetic Resonance Imaging Findings and Clinical Symptoms in Patients with Suspected Lumbar Spinal Canal Stenosis: a Case-control Study. Acta Informatica Medica, 27(4).

McCall, I. W. (2000). Lumbar herniated disks. Radiologic Clinics, 38(6).

Mysliwiec, L. W., Cholewicki, J., Winkelpleck, M. D., \& Eis, G. P. (2010). MSU classification for herniated lumbar discs on MRI: toward developing objective criteria for surgical selection. European spine journal, 19(7).

Nazarenko, N. V., Remnov, A. G., \& Golyakhovskiy, A. V. (2017). Elektroneyromiograficheskaya otsenka funktsional'nogo sostoyaniya poyasnichnogo otdela pozvonochnika [Electroneuromyographic assessment of the functional state of the lumbar spine]. Saratovskiy nauchno-meditsinskiy zhurnal, 13(1). [In Russian].

Nikolayev, S.G. Praktikum po klinicheskoy elektromiografii [Tutorial on Clinical Electromyography]. Ivanovo, 2003. [In Russian].

Nordberg, C. L., Boesen, M., Fournier, G. L., Bliddal, H., Hansen, P., \& Hansen, B. B. (2020). Positional changes in lumbar disc herniation during standing or lumbar extension: a cross-sectional weight-bearing MRI study. European Radiology.

Ponomarenko, S. O. (2015). Porivnyal'nyy analiz promenevykh metodiv doslidzhennya pry stenozi khrebetnoho kanalu poperekovoho viddilu khrebta [Comparative analysis of radiological methods of research in stenosis of the spinal canal of the lumbar spine]. Ukrayins'kyy radiolohichnyy zhurnal, (23, vyp. 1). [In Ukrainian].

Ravindra, V. M., Senglaub, S. S., Rattani, A., Dewan, M. C., Härtl, R., Bisson, E., ... \& Shrime, M. G. (2018). Degenerative lumbar spine disease: estimating global incidence and worldwide volume. Global spine journal, 8(8).

Sipityy, V.I., Moroz, I.S., Yakimiv, G.A., Pecherskiy, B.V. Diagnostika i khirurgicheskoye lecheniye stenoza pozvonochnogo kanala. (2004). Ortopediya, travmatologiya i protezirovaniye. 4. [In Russian].

Steurer, J., Roner, S., Gnannt, R., \& Hodler, J. (2011). Quantitative radiologic criteria for the diagnosis of lumbar spinal stenosis: a systematic literature review. BMC musculoskeletal disorders, $12(1)$.

Yegorov, A.V. (2014). Kompleksnoye ispol'zovaniye endovideoneyrokhirurgicheskikh tekhnologiy pri lechenii patsiyentov s gryzhami poyasnichnykh mezhpozvonkovykh diskov [Comprehensive use of endovideoneurosurgical technologies in treatment of patients with 
hernias of the lumbar intervertical discs] : thesis for the degree of candidate of medical sciences,

Zareth, N., Hilibrand, A., Gustavel, M. et al. (2003). Variation in Surgical Decision Making for Degenerative Spinal Disorders. Lumbar Spine. Part 1. 2208-2214.

Zhou, Z., Deng, H., Yang, W., Wang, Z., Lin, L., Munasinghe, J., ... \& Chen, X. (2020). Early stratification of radiotherapy response by activatable inflammation magnetic resonance imaging. Nature communications, 11(1).

Zileli, M., Crostelli, M., Grimaldi, M., Mazza, O., Anania, C., Fornari, M., \& Costa, F. (2020). Natural Course and Diagnosis of Lumbar Spinal Stenosis: WFNS Spine Committee Recommendations. World Neurosurgery. 